\title{
Influence of Internal Defects of Basic Metal of the Equipment on Its Operational Properties
}

\author{
S.I. Valeev ${ }^{1, a^{*}}$ \\ ${ }^{1}$ Kazan National Research Technological University, Kazan, Republic of Tatarstan, Russian \\ Federation \\ avsi73@mail.ru
}

Keywords: Defect, Accident, Stress, Operation, Delamination Of The Base Metal, Technical Diagnostics

\begin{abstract}
The paper deals with the issue of safe operation of technological equipment with a defect in the base metal of the delamination type. Mathematical modeling of the stress-strain state in the defect zone by the finite element method in ANSYS software package is carried out. The article presents and analyzes the obtained graphs of the distribution of stress intensity factors. Based on the analysis of the obtained dependences, it is shown that stratification of the base metal does not have a significant effect on the performance of the process equipment.
\end{abstract}

Currently, equipment for potentially hazardous chemical, petrochemical, oil and gas processing industries is worn out by $80-90 \%$. This leads to a decrease in the reliability and durability of equipment and, in turn, to an increase in industrial accidents [1,2,6,7,11].

Equipment for chemical, petrochemical, oil and gas processing industries is made mainly of various types of metals. The causes of emergencies are mainly associated with formation and development of defects that may appear not only during operation, but may also be initially present in the metal of the equipment that was not noticed during the incoming inspection $[1,4,7,8]$. All this can lead to depressurization of technological equipment, release and spill of explosive and fire hazardous substances.

Defects and destruction of materials can be caused by metallurgical reasons, when there are defects in the workpieces.

One of the most dangerous defects of metallurgical origin, leading to accidents, is a crack-like defect such as delamination of the base metal or welded joint $[4,9,10]$.

In literary sources, there are several definitions of delamination, among which the most accurate and complete is the following: delamination is an internal discontinuity of the base metal of the equipment wall, oriented in the direction of the fiber, which occurs during processing of an ingot with pressure, which had shrinkage cavities or looseness, as well as when rolling of non-metallic inclusions and gas bubbles.

According to the normative technical documentation, the main measures to ensure safe operation of technological equipment are their timely technical diagnostics during manufacture, during operation and at the end of their service life [2].

When carrying out technical diagnostics, an important step is to carry out non-destructive testing of the base metal and welded joints of technological equipment. Non-destructive testing during technical diagnostics allows detecting defects without violating their suitability for intended use at all stages of the equipment life cycle. 
As noted earlier, the most acceptable method for detecting delamination is the ultrasonic method of non-destructive testing $[9,10]$.

In accordance with federal norms and rules in the field of industrial safety, if a crack-like defect of delamination type is detected during technical diagnostics of technological equipment, then operation of such equipment must be prohibited, since this defect is unacceptable.

Usually, the operation of such equipment is possible after repair by removing the defective area and welding in its place a so-called patch from a similar material or replacing this equipment. Both options are associated with withdrawal of the equipment for a long time from technological process and shutdown of production, which is not always the correct and reasonable decision, especially in modern economic conditions.

The accumulated experience in the field of fracture mechanics and automated analysis enables modeling and assessing the possibility of conditions for further operation of technological equipment with a delamination type defect $[3,5,9,10]$.

Mathematical modeling of the stress-strain state in the defect zone was carried out by the finite element method implemented in ANSYS software package.

ANSYS is a unique finite element system that covers many phenomena of a different physical nature, such as fluid dynamics, strength, electromagnetism, and thermal physics. It has the ability to solve related problems that combine all the listed types of phenomena. The standard calculation procedure is divided into three stages: building a model; application of loads and obtaining a solution; viewing and analysis of results. It has been established that the main criterion parameter for analyzing brittle and quasi-brittle fractures, where the operating temperature does not exceed the first critical one, is the stress intensity factor K (SIF).

For example, with the help of ANSYS software package [9], the possibility of safe operation of equipment with delamination of the base metal, depending on the ratio of delamination length to the length of the shell of the equipment body, was considered. The calculation results showed that the maximum values relative to other stress intensity factors reach the stress intensity factors of the second type - KII.

In work [10], the possibility of safe operation of equipment with stratification of the base metal, depending on the depth of its occurrence in the base metal, was considered, modeling was also carried out in ANSYS software package. The data obtained show that the maximum values relative to other stress intensity factors are reached by the stress intensity factors of the second type - KII (longitudinal shear crack) located closer to the inner wall of the shell.

According to the results of the above calculations, it was established $[3,5,9,10]$ that the values of the stress intensity factors were small compared to the critical ones for a given material, further growth of a delamination-type defect was excluded, which meant that delamination did not significantly affect the load-carrying capacity of the equipment.

It should be noted that the above works were carried out under the same conditions, simulation parameters and were interrelated $[9,10]$. In particular, a model of a half shell was considered with the corresponding boundary conditions recorded on the plane of symmetry. To simulate the reaction of bottoms, the corresponding tensile stresses were applied to the end planes. The modeling did not take into account the effect of stress concentrators (joints, fittings, supports, etc.). To create the correct mesh in the delamination front area, 2-D elements with offset central nodes (in order to implement the shape function with a root feature) PLANE82 and 3-D elements SOLID186 with the addition of contact elements CONTA174 and TARGE170 were used. A nonlinear contact static problem was solved without taking into account plastic deformations in the delamination front zone. 
The purpose of this work is to continue the development of a method for determining parameters of fracture mechanics KI, II, III and to create a system for their automated calculation to predict the resource of technological equipment with crack-like defects such as delamination, other things being equal, a different ratio of delamination axes relative to the shell axis is considered.

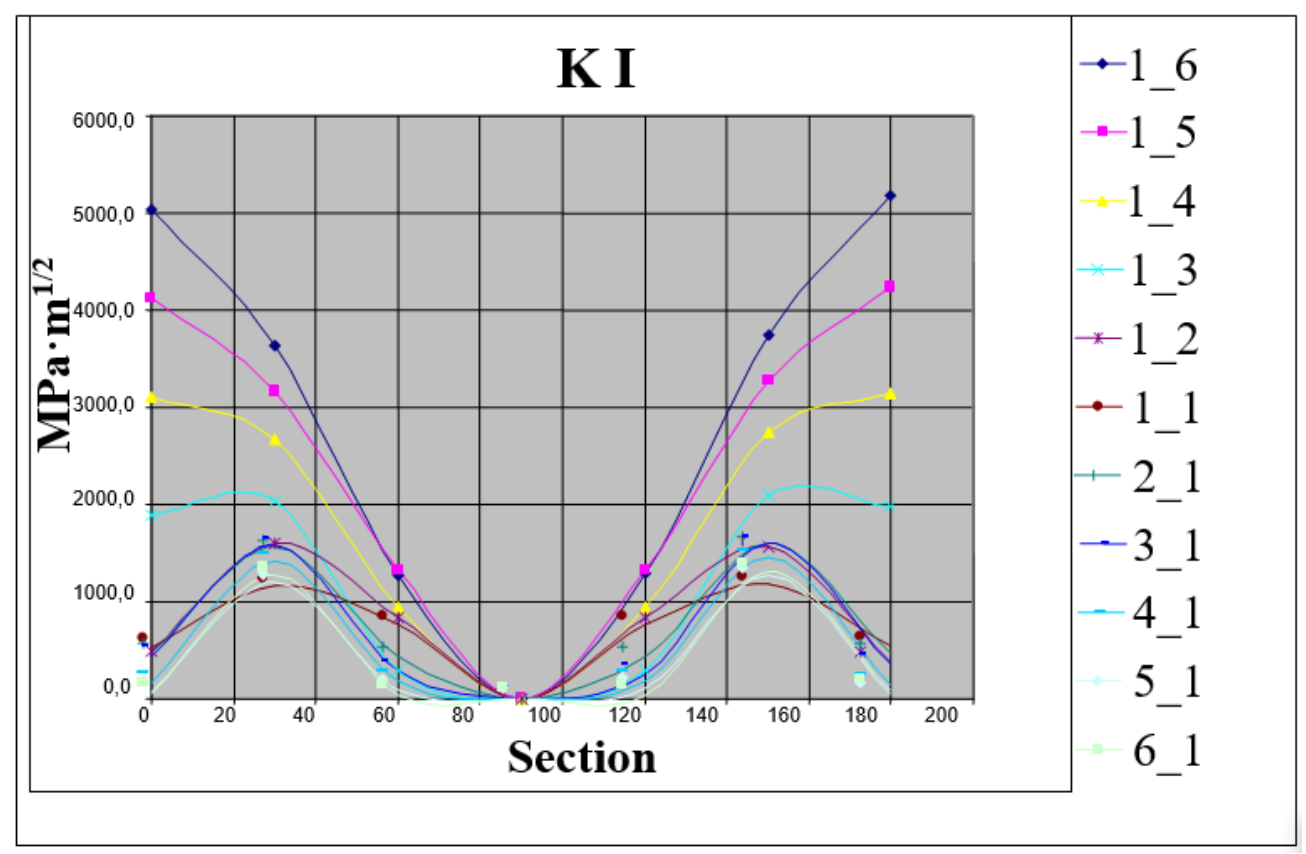

Fig. 1. Calculated values of stress intensity factor KI for different ratios of delamination axes relative to the shell axis.

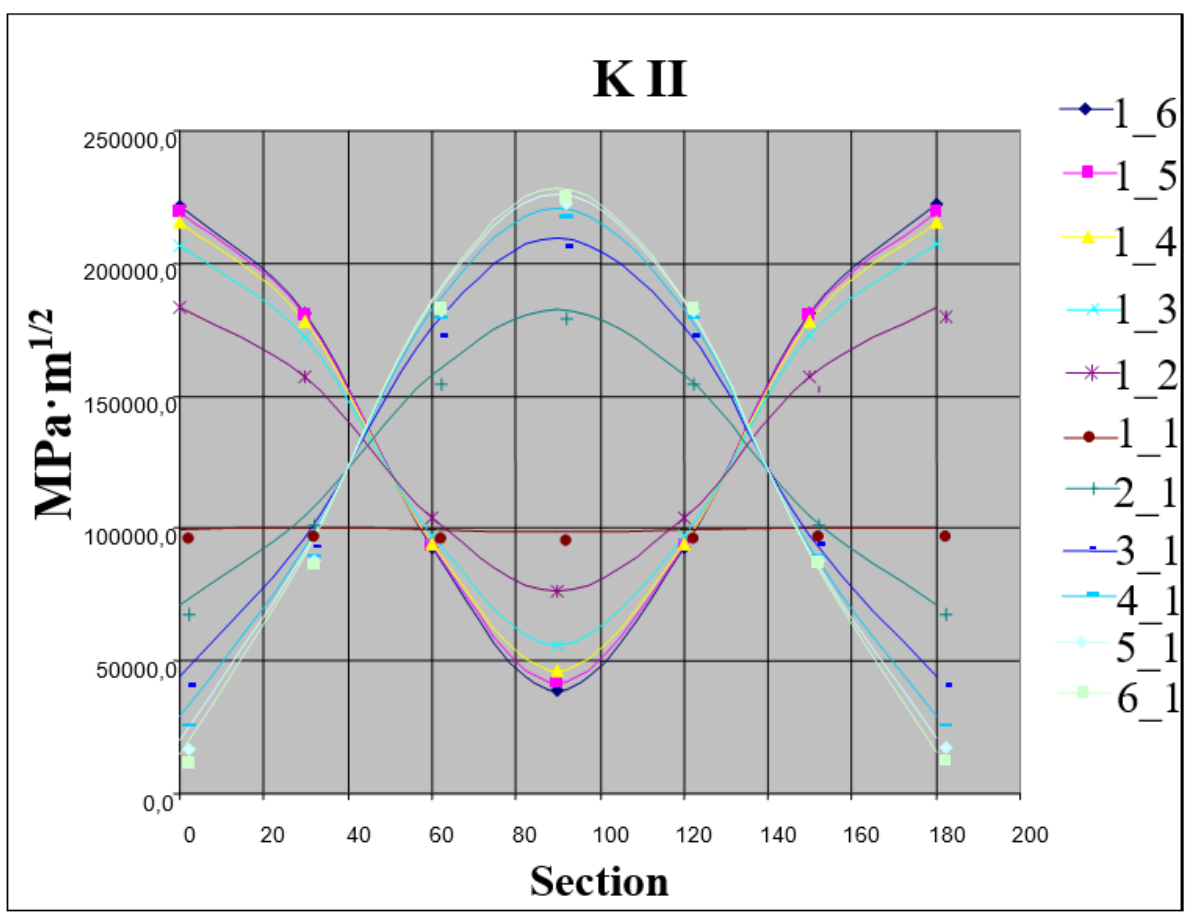

Fig. 2. Calculated values of stress intensity factor KII for different ratios of delamination axes relative to the shell axis 


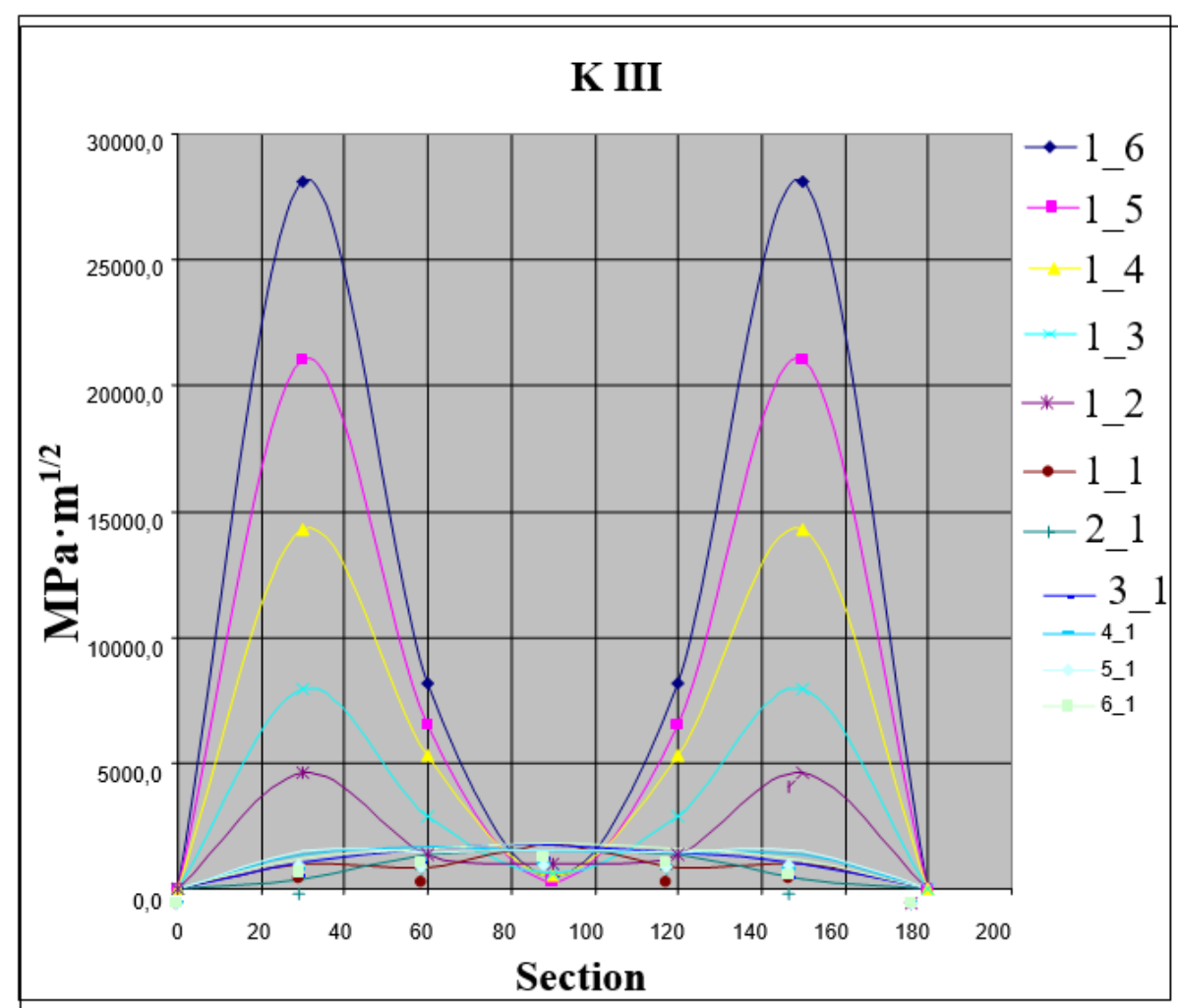

Fig. 3. Calculated values of stress intensity factor KIII at various ratios of delamination axes relative to the shell axis

Figures 1, 2, 3 show the calculated values of stress intensity factors (SIF) KI, KII and KIII for 7 points along the delamination front located every $30 \mathrm{deg}$ from 0 to $90 \mathrm{deg}$ relative to the delamination axis passing along the normal to the plane through its center. The values of stress intensity factors were obtained at various ratios of delamination axes (relative to the shell axis) from $1 / 6$ to $6 / 1$. The obtained calculation results showed that the maximum values of the stress intensity factors relative to others were reached by the KIII-transverse shear crack oriented in the annular direction.

Analysis of the obtained dependences and the previously obtained results [9, 10] enables one to conclude that, all other things being equal, the stress intensity factors SIF II and III prevail, which means that a delamination type defect does not have a significant effect on the bearing capacity of the equipment while it is local and does not spread.

\section{References}

[1] Ainsworth, R.A., The Treatment of Thermal and Residual Stresses in Fracture Assessments / Engineering Fracture Mechanics, Vol. 24, No. 1, pp. 65-76, 1986. https://doi.org/10.1016/00137944(86)90008-1

[2] Federal Law dated 21.07.1997, No. 116-FL “On Industrial Safety of Hazardous Production Facilities", as amended;

[3] Kaplun A.B. ANSYS in the hands of an engineer. Practical Guide / A.B. Kaplun, E.M. Morozov, M.A. Olfer'eva // M.: Editorial Publ., URSS. - 2003. - 272 p. 
[4] Kharlamov I.E., Valeev S.I. Calculation of strength of shell suffering exfoliation / Chemical and Petroleum Engineering, Vol. 54, Nos. 3-4, pp. 278-282, July 2018.

https://doi.org/10.1007/s10556-018-0475-2

[5] PNAE G-7-002-86 Standards for calculation of the strength of equipment and pipelines of nuclear power plants. Moscow, ENERGOIZDAT, 1989.

[6] Ponikarova A S, Zotov M A and Salin A A 2020 Management model of sustainable development of petrochemical industry enterprises J. Phys.: Conf. Ser. 1679052031. https://doi.org/10.1088/1742-6596/1679/5/052031

[7] Shipilov S.A. and May I.L. Structural integrity of againg buried pipelines having cathodic protection//Engineering Failure Analysis.-2006.-13.-pp.1159-1176.

https://doi.org/10.1016/j.engfailanal.2005.07.008

[8] Valeev, S.I. Investigation of cylindrical hydrocyclone for emulsion separation / IOP Conference Series: Materials Science and Engineering, 2020,971(5),052007. https://doi.org/10.1088/1757-899X/971/5/052007

[9] Valeev, S.I. Risks during the operation of technological equipment at a hazardous production facility / Journal of Physics: Conference Series, 2020, 1679(4),042028. https://doi.org/10.1088/1742-6596/1679/4/042028

[10] Valeev, S.I., Kharlamov, I.E. Operation of process equipment with crack-like defects / IOP Conference Series: Materials Science and Engineering, 2020, 971(4),042037. https://doi.org/10.1088/1757-899X/971/4/042037

[11]Zotov M A, Ponikarova A S, Kadeeva E N 2020 Balanced management of innovative sustainable development of the petroleum and gas chemical complex IOP Conference Series: Materials Science and Engineering 971(5) 052023. https://doi.org/10.1088/1757$899 X / 971 / 5 / 052023$ 